\title{
MULHERES NA POLÍTICA: HISTÓRIAS DE PROTAGONISMO FEMININO NA AMAZÔNIA E A LUTA CONTRA O PRECONCEITO DE GÊNERO NAS INSTÂNCIAS DE PODER POLÍTICO
}

\author{
WOMEN IN POLITICS: STORIES OF FEMININE PROTAGONISM IN THE AMAZON \\ AND THE FIGHT AGAINST GENDER PRECONCEPTION IN POLITICAL POWER \\ BODIES
}

\section{R.de SOUZA ${ }^{1, *}$}

'Mestra em Sociedade e Cultura na Amazônia- UFAM, Pós-graduada em Didática do Ensino Superior, Assistente social, Consultora na área de formação e qualificação profissional na empresa MS Treinamento e Desenvolvimento.

\author{
ARTICLE INFO \\ Article history: \\ Received 2018-04-13 \\ Accepted 2018-04-30 \\ Available online 2018-05-02 \\ *Autor correspondente: \\ E-mail: luzvida1977@hotmail.com
}

Palavras-chave: Gênero. Protagonismo político. Política.

Keywords: Genre. Political. protagonism. Policy.

RESUMO. As mulheres brasileiras conquistaram o direito ao voto em 1932, tendo sua consolidação em 1934. Somente em 1995, com a provação da Lei 9.100, de 29 de setembro, obtiveram a garantia de cota de $20 \%$ de gênero nas chapas das candidaturas. Após dois anos, em 1997, foi aprovada a Lei 9.504, passando a cota para $30 \%$. No entanto, em qualquer aspecto avaliado, a conclusão é sempre a mesma: houve ganhos, mas em ritmo muito inferior ao desejado. Há pelo menos duas suposições a serem consideradas sobre esta problemática. A primeira está relacionada com o sistema político de cotas brasileiro que é extremamente conservador em relação às mulheres, de face androcêntrica e machista. A outra suposição está vinculada à situação das mulheres dentro dos partidos políticos, as quais possuem posição de coadjuvantes, assumindo um papel subalternizado, na medida em que não ascendem ao cargo de presidente de seus partidos. Diante desse quadro de desigualdade, o presente estudo tem como objetivo descrever o protagonismo político de quatro mulheres junto ao parlamento brasileiro. Para atingirmos os objetivos aqui propostos, realizamos entrevistas semiestruturada a quatro mulheres (duas ex-parlamentares e duas parlamentares) para sabermos sobre a atuação política de cada uma junto ao parlamento. Dos múltiplos resultados apresentados pelo estudo, conclui-se que a mulher na Amazônia tem uma longa história de participação política e que independente das diferentes décadas de atuação, foram capazes de enfrentar todas as formas de preconceito dentro dos partidos políticos e da própria casa parlamentar para se firmarem enquanto parlamentares.

ABSTRACT. Brazilian women gained the right to vote in 1932, having been consolidated in 1934 . Only in 1995, with the probation of Law 9,100, of September 29, they obtained the guarantee of $20 \%$ gender quota in the slates of the candidatures. After two years, in 1997, Law 9,504 was approved, passing the quota to $30 \%$. However, in any evaluated aspect, the conclusion is always the same, that is, there were gains, but at a much lower rate than desired. There are at least two assumptions to be made about this problem. The first is related to the Brazilian quota system, which is extremely conservative in relation to women, with an androcentric and sexist face. The other assumption is linked to the situation of women within political parties, who have a position as coadjuvants, assuming a subordinate role, insofar as they do not ascend to the position of president of their parties. Given this framework of inequality, the present study aims to describe the political role of four women in the Brazilian parliament. To achieve the objectives proposed here, we conducted semi-structured interviews with four women (two former members of parliament and two parliamentarians) to learn about each other's political activities at the parliament. From the multiple results presented by the 
study, it is concluded that women in the Amazon have a long history of political participation and that, regardless of the different decades of practice, they were able to face all forms of prejudice within political parties and in the parliamentary house itself to stand as parliamentarians.

\section{INTRODUÇÃO}

Apesar dos avanços da participação das mulheres no mercado de trabalho e nos cursos de formação superior, a participação delas no parlamento ainda é muito diminuta. Infelizmente a casa parlamentar tem contado com um número bem reduzido de mulheres a cada eleição, mesmo após a criação da lei de cotas de gênero. Mesmo com uma política de ação afirmativa, observa-se que quando o assunto é candidatura feminina os partidos políticos passam a sair em busca de mulheres apenas para o preenchimento das cotas, excluindo-as do processo de candidatura propriamente dito já que elas não recebem o mesmo tratamento dispensado aos demais correligionários do partido.

Algumas mulheres no Amazonas se atreveram a investir em suas candidaturas e através de muita luta conseguiram se eleger, tornaram-se vítimas também do preconceito dentro dos espaços de poder político. Este estudo assume o propósito de verificar a luta de mulheres para se firmarem no campo político dando ênfase ao protagonismo político de quatro parlamentares representantes do Amazonas na Câmara dos Deputados e Senado Federal. Para obtenção das informações aqui contidas, entrevistamos quatro parlamentares para sabermos sobre seus desafios e enfrentamentos junto ao preconceito de gênero na Política partidária que ainda tem sido muito presente nesses espaços de poder.

Dos resultados apresentados, constatou-se que a mulher nos espaços de poder político, seja ele dentro dos partidos ou na própria casa parlamentar, enfrenta diversos desafios ao impor a sua presença como também merecedora de direitos. Nos mostra que as mulheres apesar de se encontrar em caráter de desigualdade quantitativa com relação aos homens, sabem articular, discursar, debater e exigir direitos diante da plenária, atitudes até então, atribuída somente aos homens.

Eunice Michiles, a primeira senadora do Brasil carrega consigo toda a experiência de uma mulher que por conta de seu pioneirismo sofreu, mas combateu as mais diferentes formas de preconceito dentro de seu próprio partido e por parte de seus colegas senadores. A ex-deputada federal e constituinte Beth Azize, conhecida como um ícone da política amazonense, também teve que travar verdadeiras batalhas para firma-se como parlamentar. Mesmo sendo dona de um protagonismo político extenso, Beth Azize durante o início de sua carreira política sofreu diversas formas de preconceito por questões de gênero e sexismo.

A deputada federal Conceição Sampaio que atualmente é a única deputada representante do Estado do Amazonas na Câmara Federal, também nos traz relato de sua experiência enquanto parlamentar e mulher e sua luta para se firmar no campo político tão dominado pelos homens. A senadora Vanessa Grazziotin que iniciou sua carreira política no movimento estudantil e posteriormente no movimento sindical, apesar da luta pela inserção de mulheres na política partidária nas décadas de 1980 foi a única a nos relatar em entrevista que não sofreu resistência por parte do partido com relação a sua candidatura. As histórias de protagonismo político dessas mulheres relatado neste estudo busca contribuir com as discussões entorno da participação feminina no parlamento que ainda não é satisfatória e mais que isso, não é bem aceita pelos parlamentares 
homens mesmo após oitenta anos da chega da primeira mulher nos espaços de poder político, a bióloga Berta Lurtz, pioneira na luta pelo sufrágio no Brasil.

\section{FUNDAMENTAÇÃO}

Este estudo está sendo realizado sob o aporte teórico-metodológico de três conceitos ou categorias analíticas, a saber: gênero, protagonismo político, política.

A história das mulheres é regida por muitas lutas de combates às opressões, pois a medida que as civilizações se desenvolveram as relações entre homens e mulheres, conhecida como relações de gênero também foram tomando forma. Stearns $(2012$, p.31) assinala que "com a descoberta da agricultura, caça, e fogo, as comunidades passaram a se fixar num determinado território. Aos homens cabiam sair pra caçar e as mulheres dedicava-se ao cultivo da terra, cuidar das crianças e preparo dos alimentos".

Com o surgimento das grandes civilizações e do reconhecimento da maternidade como prática doméstica, as mulheres perderam importância no espaço público e passaram a ser consideradas criaturas inferiores aos homens. Essa forma de dominação ficou conhecida como patriarcado que de acordo com os estudos de Torres (2009, p.105), "o patriarcado é um sistema de dominação sofisticado e complexo, bem mais forte e virulento do que o racismo e o capitalismo".

Safiotti (2004) assinala que a desigualdade entre homens e mulheres não é algo natural, mas cultural, imposta pelas estruturas de poder e pelos agentes envolvidos nessa trama de relações sociais. Essa desigualdade chega a ser bem mais expressiva nos espaços de poder político que na maioria das vezes exclui as mulheres de participarem do processo eleitoral de forma igualitária aos homens. Na Amazônia podemos observar que existem diferentes formas de participação política e as mulheres são as que mais exercem esse trabalho político que na maioria das vezes não são reconhecidos, como por exemplo, os trabalhos de base realizados por mulheres dentro das comunidades.

Os estudos de Costa (2005) indicam que no século XIX na Amazônia, as mulheres participavam significativamente do processo político exercendo trabalhos de apoio às candidaturas de seus esposos e filhos. "Elas se encarregavam de preparar os grandes almoços para os políticos que vinham de fora, fazer campanha na comunidade e colaborar no apoio logístico para os eleitores nos dias das eleições" (COSTA, 2005, p. 73). Quase sempre, esse trabalho realizado pelas mulheres era para beneficiar seus maridos e filhos através de nomeações a cargos públicos. De fato, não havia nenhum reconhecimento do trabalho feminino por parte dos políticos, já que não eram elas as beneficiadas com os cargos e apoio político.

A expressão participação política é geralmente usada para designar uma variada série de atividades como: o ato do voto, a militância num partido político, a participação em manifestações, discussão de acontecimentos políticos, até o apoio a um determinado candidato (BOBBIO, 1998). A luta pela emancipação política foi de extrema relevância para que conquistassem direitos essenciais como o direito ao voto e de se candidatar. "O movimento feminista tem contribuído para desconstruir o mito do apoliticismo feminino, demonstrando que as mulheres participam da vida política, inclusive em esferas não reconhecidas como espaços políticos" (PINHEIRO, 2006, p.210).

Muitas mulheres hoje que conseguiram chegar ao parlamento municipal e estadual foram militantes que desempenharam papel importante dentro dos sindicatos, dos movimentos feministas e 
estudantis. "Outra forma encontrada pelas mulheres de ascender à elite política foi a realização de trabalho de base, sua presença em associações de bairros, em organizações não governamentais, contribuiu para o processo de empowerment feminino" (PINHEIRO,2006, p.43). O sindicato é uma das instituições que tem servido para socializar politicamente as mulheres, cujo processo de luta por reivindicações conduz enormemente à conscientização política delas. Mas também é um espaço onde as mulheres mais sofrem preconceito. Torres (2005) assinala que o medo dos homens pela perda do espaço sindical para as mulheres faz com que os mesmos inibem a participação delas em muitas atividades desenvolvidas pelo sindicato.

Em 1995 a aprovação da Lei 9.100 de 29 de setembro, que garantiu a cota de $20 \%$ de gênero nas chapas das candidaturas, veio possibilitar que mais mulheres pudessem se inserir na política. Após dois anos, em 1997, aprovou-se a Lei 9.504, de 30 de setembro, alterando o quantitativo de $20 \%$ para $30 \%$ da cota de gênero. Essas ações afirmativas contribuem para que mais mulheres possam se inserir na política e poder criar leis que contemplem cada vez mais a reivindicação do movimento feminista e das mulheres de forma geral, mas ainda que exista uma política de ações afirmativas, o quantitativo de mulheres nos espaços de poder político ainda é bem inferior com relação aos homens.

A política criada pelos gregos foi uma forma de separar o público do privado, o senhor chefe de família (Privado) do Senhor do poder pertencente à coletividade (público). A participação ao direito de decisão política era somente dada aos cidadãos nascidos gregos, como homens livres maiores de 18 anos, ficando excluídos os estrangeiros, mulheres e os escravos. Aristóteles fazia distinção entre homem e mulher. Em sua obra A Política, Aristóteles traz inúmeros trechos dessa distinção como "entre os sexos também o macho é por natureza superior e a fêmea inferior, aquele domina e esta é a dominada, o mesmo princípio se aplica a todo o gênero humano" (ARISTÓTELES, 1985, p.1254).

Ser político, viver na polis, significava que tudo se fazia por meio de palavras e persuasão, e não com a força e a violência. "A polis era o espaço da liberdade e da democracia, um espaço exclusivamente masculino" (CHAUÍ, 2010, p.234). A política é um poder, poder que exerce um chefe de família no seio familiar, poder que exerce um rei no que toca aos seus súditos. O poder exercido pelo chefe do lar servia para governar a família e seus escravos, na vida privada cabia ao homem a manutenção individual (o sustento) e a mulher a sobrevivência da espécie (o Parto). Conforme nos explica Arendt (2010, p.33), "a distinção entre as esferas privada e pública da vida, corresponde aos domínios da família e da política, que existiram como entidades diferentes e separadas, pelo menos desde o surgimento da antiga cidade-estado".

Apesar de inúmeros conceitos em torno do significado de política, o mais importante é compreendermos que é ela a política que rege toda a relação social num Estado-Nação. Trata-se de um conceito associado à participação de todos os cidadãos no que concerne aos direitos e deveres é por isso que política e direito não se separam.

\section{MÉTODO}

Este estudo assume o aporte teórico-metodológico das abordagens qualitativas sem excluir os aspectos quantitativos. Para dar entendimento e baliza ao nosso estudo elegemos autores como Aristóteles (1985), Arendt (2010), Bobbio (1998), Torres (2005,2009), dentre outros que darão suporte à pesquisa. 
Como instrumento de coleta de dados utilizamos a técnica de entrevista semiestruturada juntamente a quatro mulheres composta por duas parlamentares e duas ex-parlamentares, com intuito de levantar dados sobre suas experiências no parlamento. Reafirmamos o nosso compromisso e respeito aos princípios éticos da pesquisa onde cada sujeito aqui mencionado, aceitou participar deste estudo e assinaram o Termo de Consentimento Livre e Esclarecido. Lembrando que este estudo é parte da dissertação de mestrado intitulada "A presença da mulher na política: o protagonismo de Eunice Michiles no Senado Federal" defendido em setembro de 2016, através do Programa de Pós-graduação em Sociedade e Cultura na Amazônia- UFAM.

\section{A luta feminista pela paridade de gênero NA Política Representativa BRASILEIRA}

A história das mulheres é regada de muitas lutas e de combates às opressões, pois a medida que as civilizações se desenvolveram as relações entre homens e mulheres, conhecida como relações de gênero também foram tomando forma. No Brasil, assim como em vários países latinoamericanos, as primeiras manifestações feministas aparecem na metade do século XIX. Teve como foco a luta das mulheres pelos direitos políticos mediante a participação eleitoral como candidatas e eleitoras. Essa fase da história do movimento feminista brasileiro foi organizada por mulheres da classe média e alta, algumas filhas de políticos e intelectuais da sociedade brasileira. A conquista mais marcante dessa época foi o direito ao voto concedido às mulheres em 1932.

No decorrer dessas décadas, outras poucas conquistas foram sendo adquiridas através da luta feminista como, por exemplo, a Lei 9.100/95 que em seu § $3^{\circ}$ obriga os partidos a disponibilizarem no mínimo $20 \%$ das vagas de cada partido ou coligação para mulheres. Esse percentual foi alterado para 30\% com a aprovação da Lei 9.504/97. Apesar dos avanços, ainda sim, podemos constatar que, através dos resultados das últimas eleições no Amazonas o percentual de mulheres ocupando um lugar na casa parlamentar ainda é bem baixo. Atualmente, as mulheres representam mais da metade do eleitorado brasileiro, mas ainda sim, são minorias nos espaços de poder político. E diante de tal realidade, nos perguntamos será que mulher não vota em mulher? Certamente que sim e os homens também votam, mas a falta de apoio dos partidos para que as mulheres possam concorrer as eleições de forma igualitária com os homens é um dos primeiros entraves que dificulta a candidatura feminina.

Os partidos abrem suas portas as mulheres somente em vésperas de eleição, quando precisam preencher suas cotas e esquecem que essas mesmas mulheres a partir daquele momento têm direitos e obrigações tanto quanto os candidatos homens, mas infelizmente, ainda que tenhamos uma política de ação afirmativa, pouco ou quase nada os partidos tem feito pela mulheres além de filiá-las para cumprir o que determina a lei com a justificativa de que estão apoiando a paridade de gênero na política. De acordo com os estudos de Ferreira (2010, p. 81) "A lei de cotas é uma proposta com o objetivo de corrigir as desigualdades nas relações de gênero". Mas percebe-se que os partidos têm buscado burlar a lei quando apenas aceitam mulheres para o preenchimento das cotas e não para lançá-las como candidatas recebendo o devido apoio do partido.

O processo eleitoral vai muito além do fazer campanhas e ao ato de votar, pois os partidos pensam e agem de forma estratégica bem antes das propagandas políticas iniciarem. É através dessas estratégias políticas, que se forma o bloco político dentro dos partidos os quais são grupos for- 
mados por correligionários que se beneficiam e se fortalecem em benefício do apoio recebido pelos presidentes dos mesmos. Apesar da Lei no 9 504/1997, que estabelece que nas eleições cada partido ou coligação deverá reservar o mínimo de $30 \%$ e o máximo de $70 \%$ para candidaturas de cada sexo, muitas mulheres não tem conseguido a tão sonhada eleição e essa realidade é reflexo do pensamento androcêntrico, tão presente nas estruturas de poder político que exclui as mulheres dos espaços de poder político.

Com a minirreforma eleitoral de 2009 (Lei no 12.034/2009), a expressão "deverá reservar" foi substituída pela "preencherá", tornando esse preenchimento obrigatório. Com a norma anterior os partidos não sofriam penalidades caso não conseguissem preencher o número mínimo de mulheres em suas legendas e essa falta de obrigatoriedade só contribuiu para que se postergasse o crescimento da participação feminina na política.

Mesmo com as mudanças, muitas mulheres têm ficado de fora da carreira política, pois ainda que se faça ajustes na lei, não estamos conseguindo avançar quantitativamente com relação as candidaturas femininas já que aumentou o número de candidatas, mas esse aumento não resultou em vagas preenchidas por elas no parlamento. Essa cultura machista que envolve e que ainda predomina nas instâncias de poder político não tem permitido com que a presença feminina no parlamento avance.

Com o objetivo de estimular a participação feminina na política, a legislação brasileira que exige, desde 2009 , o mínimo de $30 \%$ e o máximo de $70 \%$ de candidatos de cada sexo em eleições proporcionais contribuiu para o aumento de candidaturas femininas em todos os estados brasileiros, porém, observou-se que o número de mulheres que apenas se filiaram a algum partido apenas para atender as exigências da lei também aumentou.

Pesquisa realizada pelo site gênero e número em 2016 apontou que alguns municípios do Estado da Paraíba, Bahia e Amazonas, por exemplo, a quantidade de candidatas sem voto em 2016 chega a ser de até $23 \%$. No Amazonas, $22 \%$ das candidatas não receberam um único voto. O que nos leva a refletir sobre o indício de uma participação eleitoral fictícia. Em Manaus, dos 41 candidatos eleitos ao cargo de vereança, apenas 04 mulheres conseguiram se eleger o que confirma a persistência da desigualdade de gênero na política partidária no município (ROSSI e MAZOTTE, 2016).

Em seu discurso realizado no dia 23 de setembro de 2016, na sede da Organização das Nações Unidas - ONU em Brasília, a ministra Luciana Lóssio, do Tribunal Superior Eleitoral - TSE, criticou a legislação eleitoral no que se refere ao incentivo à participação feminina nas eleições. Para a ministra, essa legislação é feita para não dar certo já que só tem servido para excluir ainda mais as mulheres. As palavras da ministra confirmam a baixa participação política das mulheres, já que, os partidos apenas recebem as candidaturas femininas no momento de preenchimento das cotas, e na maioria dos casos, excluem as mulheres de obterem os mesmos direitos que os seus correligionários homens. Apesar de todos os obstáculos, as mulheres com o apoio do movimento feminista brasileiro têm buscado se inserir mais nas discussões políticas do país.

\section{O PRECONCEITO DE GÊNERO JUNTO AS INSTÂNCIAS DE PODER POLÍTICO}

Muitas mulheres são usadas como massa de manobra para eleger o candidato homem. Eunice Michiles, que ficou conhecida por se tornar a primeira mulher a chegar ao Senado Federal, 
também foi uma das tantas outras mulheres que foram usadas pelo partido para apenas preencher uma legenda e teve que enfrentar diferentes formas de discriminação por ser mulher. Em entrevista, Eunice Michiles nos conta como se deu a sua candidatura ao Senado Federal:

Eu já estava me preparando para a reeleição e foi quando a ARENA que só tinha dois candidatos na sua sublegenda me fez o convite para sair candidata ao Senado. No outro partido entrou uma mulher e evangélica, a Maria Júlia. A disputa era muito acirrada, muito próxima e ninguém sabia quem ganharia. Então os membros da ARENA pensaram:

- mulher e evangélica? Dona Eunice é claro!

Eu não queria, pois como deputada estadual minha reeleição era quase certa. Mas o partido foi me mostrando que se caso eu não aceitasse, nós perderíamos a eleição, eu era a única com o mesmo perfil político da candidata do partido da oposição. Então eu aceitei, me joguei na campanha mesmo sabendo que não ganharia essa eleição, mas pensei que com isso ao menos conseguiria realizar um sonho que era ser secretária de assistência social (Eunice Michiles, Entrevista 2015).

No momento de sua candidatura em 1978, sequer existia uma política de ação afirmativa que obrigasse os partidos de tornarem possível a candidatura feminina, mas o interesse na candidatura de Eunice Michiles por parte da ARENA estava voltado para a eleição de João Bosco, o que não é muito diferente com relação às candidaturas atuais, pois ainda tem se usado a candidatura de mulheres para fortificar a candidatura masculina.

Eunice tinha seus próprios planos políticos na época, pois almejava candidatar-se a reeleição, mas os interesses partidários, que normalmente não incluem favorecer a candidatura feminina, era eleger o candidato homem. Para Perrot (1998, p.131) "essa prática ficou conhecida como síndrome de Joana d'Arc: já que nada funciona, por que não uma mulher?". O esquema de favorecimento à candidatura masculina em detrimento da feminina contribui para com a baixa participação de mulheres no campo político, já que de alguma forma, elas são usadas pelo partido para garantir a eleição dos políticos homens.

De acordo com as análises de Tabak (2002, p. 152),

A falta de credibilidade numa candidatura feminina ficou algumas vezes patente, dentro e fora do partido. Dentro do partido, persistiu ainda a tendência a instrumentalizar a mulher, isto é, utilizar o fato de que ela era candidata, para fazer as denominadas dobradinhas, para que, na prática, ela contribuísse, com seu esforço pessoal, para divulgar e ampliar a campanha de seu companheiro masculino. Ou seja, a candidatura feminina não era encarada realmente, como algo pra valer.

Essa falta de credibilidade na candidatura feminina conforme mencionado por Tabak (2002) é uma das mais diversas formas de preconceito e de discriminação contra as mulheres que entram para a política sem receber o apoio necessário para que possam concorrer as eleições em caráter de igualdade com os homens. Seguindo a mesma linha de análise, Costa (1998, p. 113) nos diz que "Os partidos políticos têm uma face de organização que privilegia a estrutura masculina". Esse privilégio tem inibido a participação feminina nos espaços de poder político e a consequência não é somente em relação a baixa participação de mulheres nas casas parlamentares, mas muitas políticas públicas que favoreçam as mulheres, a família como um todo deixam de ser criadas porque na maioria das vezes nem entram na pauta de votação dos nossos representantes políticos. 
Outro entrave às candidaturas das mulheres é a falta de orientação ou assessoria para que elas possam resolver problemas burocráticos exigidos pelo Tribunal Superior Eleitoral-TSE. Muitas mulheres filiam-se aos partidos a pedido de seus companheiros e sem entender o processo eleitoral acabam que se prejudicando por não receberem as devidas orientações para concluírem sua prestação de contas. Muitas candidaturas têm se tornado inelegível porque os candidatos desconhecem como proceder.

Um exemplo da falta de compromisso com as candidaturas femininas está na falta de apoio financeiro para suas campanhas, pois cabe ao presidente do partido direcionar o percentual dessa verba para os candidatos, mas o que tem ocorrido, é que a essa verba não tem sido distribuída de forma igualitária. Eunice Michiles que nos conta sua experiência enquanto candidata: "Meus colegas iam fazer campanhas pelo interior do Estado do Amazonas com o apoio do partido e eu só ficava sabendo quando eles retornavam da viagem" (Entrevista 2016).

Assim como Eunice Michiles, muitas outras candidatas ficam de fora da lista para o recebimento de verba de campanha. Enquanto a candidatura feminina for para os partidos políticos apenas uma necessidade para que elas possam preencher suas cotas, poucas mulheres terão acesso de forma efetiva no processo eleitoral já que sua participação em alguns casos é apenas para o preenchimento de cotas. A deputada federal Conceição Sampaio nos relatou sobre a sua experiência no início de sua candidatura quando teve que participar das eleições apenas para preencher a cota de seu partido. Vejamos,

Em 1996 eu recebi um convite. Nessa fase era mais pra emprestar o nome. $\mathrm{O}$ que a gente tanto hoje combate que muitos partidos só te usam para preencher uma cota. Eu certamente naquele momento fui mais uma a preencher uma cota. Ainda assim, em 1996 eu tive um percentual bem elevado de votos, mas não fui eleita. Em 2004, tomei a decisão de ser candidata. Aí foi uma decisão pessoal, depois de ter ido estudar um curso de direito pra entender melhor todo o processo pra não só ouvir falar, mas participar muito mais de forma protagonista do que como coadjuvante (Conceição Sampaio, Entrevista/2015).

A deputada federal Conceição Sampaio, também foi uma das tantas mulheres que apenas emprestaram seu nome para o partido, essa prática não deixa de ser uma forma de preconceito as mulheres candidatas. Essa estratégia para beneficiar os homens, ainda tem sido muito usada pelos partidos, o que enfraquece a luta feminina por direitos de igualdade na política partidária. Algumas mulheres têm conseguido superar 0 rótulo de que não são capazes de exercer uma função parlamentar, mas tem sido uma luta que não parte somente delas, mas do próprio movimento feminista que tem reivindicado maior participação política das mulheres em todas as esferas de poder.

Vale ressaltar que, apesar de muitas mulheres estarem sendo usadas como massa de manobra pelos partidos, em alguns casos, as mulheres também são articuladoras e algumas chegam até negociar com os dirigentes, futuros cargos em troca de suas candidaturas, como ocorreu com a ex-senadora Eunice Michiles, que jogou com as mesmas armas da ARENA quando pediu em troca de sua candidatura para ajudar a eleger João Bosco, a vaga de secretária de assistência social do município de Manaus. "Considerando a sujeição das mulheres aos homens um costume universal, qualquer divergência deste ponto de vista parece ser naturalmente incomum" (MILL, 2006, p.29). 
Naquele momento, Eunice sabia que não iria se eleger, mas como seu mandato de deputada estadual se encerraria, buscou articular junto ao partido, possibilidades de continuar em um cargo público.

A decisão de Eunice é a prova de que a mulher também sabe articular em meio ao jogo político em favor de seus próprios interesses, mas que essa atitude não é vista como algo comum da natureza feminina. Para Mill (2006, p.39), "o que é atualmente conhecido como natureza feminina é uma coisa eminentemente artificial, resultado da repressão forçada em algumas direções e apresentada como não natural em outras".

As campanhas são para as mulheres, apenas o início de seus desafios, pois a falta de recursos para investir na divulgação, o tempo para expor suas propostas no horário político são um dos grandes percalços enfrentados pelas candidatas que se sentem excluídas dentro do próprio partido por não receberem o mesmo apoio dado aos homens. Num momento em que eram permitidos os famosos comícios, muitas mulheres subiam aos palanques apenas para "enfeitar" o lugar repleto de homens, pois se quer podiam falar. Muitas realizavam suas campanhas com a ajuda de seus parentes e amigos já que os partidos se eximiam de qualquer responsabilidade de apoiá-las.

Elizabeth Azize, uma das figuras mais emblemáticas da política amazonense também tem uma grande história de protagonismo político. Foi vereadora em 1976 pelo MDB, elegeu-se deputada estadual em 1978 pelo mesmo partido cumpriu dois mandatos de 1979 a 1987, pelo já então Partido do Movimento Democrático Brasileiro o PMDB. Em 1983 foi eleita Presidente da Assembleia Legislativa tornando-se a primeira mulher a presidir uma Assembleia Legislativa no Brasil. A exparlamentar nos relatou que por diversas vezes se sentiu incomodada e constrangida pela imprensa local e nacional. "Eu pensava comigo o porquê desses estardalhaços todo, pois deveria ser normal o fato de eu ser uma mulher ter conquistado um lugar na política, mas não era, e eu dava as entrevistas com muita revolta" (Entrevista, 2015). A sociedade, o parlamento e a imprensa são instituições androcêntricas matizados por uma moral burguesa que credita às mulheres o opróbio do preconceito e discriminação (SOUZA, 2016).

A imprensa não tem encarado a participação feminina nos espaços de poder político como uma conquista de direitos, o que normalmente tem feito durante décadas é transformar a chegada das mulheres no parlamento como um acontecimento social como fez com a chegada de Eunice Michiles em 1979 e posteriormente com Dilma Rousseff em 2011.

A luta pela igualdade tem sido dentro e fora do parlamento, pois enquanto mulher, não basta eleger-se, mas conseguir ser ouvida, respeitada e receber os mesmos direitos como parlamentar. Conforme análise de Miguel e Birolli (2014, p.63), "desde as primeiras manifestações de inconformidade com a dominação masculina, as mulheres reivindicam acesso a liberdades iguais aquelas de que os homens desfrutam". Ainda que muitas mulheres tenham conquistado esse espaço, as mesmas ainda continuam sofrendo várias formas de preconceito dentro das casas parlamentares já que muitas não são ouvidas e em alguns casos são desrespeitadas pelos próprios colegas.

A luta pela paridade de gênero no parlamento brasileiro tem sido uma das bandeiras de luta da senadora Vanessa Grazziotin ( $P C$ do $B-A M$ ), que tem viajado pelas principais capitais brasileiras para divulgar a campanha lugar de mulher é na política. Para a senadora a garantia de vagas para as mulheres na política deve ser no próprio parlamento, pois só assim garantiria as mulheres o direito de 
maior participação nos cargos parlamentares. Em entrevista a senadora nos relata sobre a luta pela paridade de gênero na política. Vejamos,

A nossa luta é tentar garantir um número de cadeiras dentro do parlamento para que as mulheres possam se sentir seguras para concorrer, pois não é que elas não querem se candidatar, elas não querem é se submeter ao ridículo. O partido não abre espaço para elas na divisão, só as procuram nas vésperas de campanha eleitoral e elas vão se candidatar sabendo que não vão ter apoio, não vão ter dinheiro para fazer campanhas. Então se você tem vagas garantidas, isso muda porque o partido também terá que mudar sua forma de agir no o que se refere às candidaturas femininas.

Para a senadora, somente a garantia de vagas no parlamento poderá mudar o quadro de desigualdade de gênero que ainda persiste na política brasileira. Pois as regras hoje vigentes não garantem as mulheres 0 acesso às casas parlamentares. Se não recebem apoio de seus partidos muitas mulheres não vão se quer candidatar-se, pois fazer uma boa campanha por menor que seja, requer verba para custear as despesas que dela provém. Conforme os estudos de Grossi e Miguel (2000), as mulheres ao longo de suas experiências na política têm percebido a importância e a necessidade de um apoio contínuo por parte dos partidos para que elas possam mostrar seu trabalho e se reeleger.

No parlamento, temos acompanhado o descaso por parte dos parlamentares em aprovar propostas, emendas e projetos que beneficiem as mulheres, pois o empoderamento delas abriria espaços para que elas pudessem estar presentes em canais de participação política até então, dominado pelos homens. Nosso parlamento hoje, dominado por homens conservadores e de elite tem dificultado bastante o avanço de novas conquistas feministas.

A exclusão das mulheres dos espaços de poder é histórica. Em entrevista a PERROT (1998, p.118), Lebrun afirma que "O acesso das mulheres ao poder político sempre e em toda parte foi difícil. A cidade grega, primeiro modelo de democracia, excluía-as radicalmente". Ainda que tenhamos conquistado alguns avanços, no mundo contemporâneo a participação feminina nas instâncias de poder está longe de ser igualitária.

Eunice Michiles, Beth Azize, Conceição Sampaio e Vanessa Grazziotin, participantes deste estudo tornaram símbolo de mulheres na luta pela participação feminina na política, em suas trajetórias, combater a desigualdade de gênero as tornaram exemplo de mulheres no parlamento. Atualmente a deputada Conceição Sampaio tem apresentado projetos voltados para a família, para o trabalhador rural do Amazonas e alguns projetos que beneficie as mulheres.

A luta das mulheres pela presença nos espaços de poder é contínua, pois a cada momento, novos obstáculos vão surgindo para que as mulheres permaneçam excluídas das decisões políticas do país, pois são eles, os homens, que estão em maioria naquele espaço de poder. Atualmente, nossa política tem demonstrado o quanto a presença feminina no parlamento brasileiro incomoda os grupos conservadores que tentam impedir que novos projetos que beneficiem a garantia de direitos não somente das mulheres quanto dos trabalhadores, crianças, idosos, LGBT, sejam votados. Apesar dos desafios enfrentados pelas mulheres para se permanecerem nos espaços de poder político, muitas parlamentares lutaram e lutam pela emancipação feminina o que as tornam grandes guerreiras na luta pela igualdes de gênero no Amazonas. 


\section{CONSIDERAÇÕES FINAIS}

A luta pela igualdade de gênero tem sido dentro e fora do parlamento, pois enquanto mulher, não basta eleger-se, mas conseguir ser ouvida, respeitada e receber os mesmos direitos como parlamentar. O presente estudo nos mostrou que a falta de apoio por parte dos partidos tem contribuído com a baixa participação de mulheres nas instâncias de poder político e essa baixa representatividade tem impactado nos avanços de novos projetos que aumente a garantia de direitos femininos. Conclui-se também que no Amazonas, algumas mulheres como Eunice Michiles e Beth Azize tornaram-se mulheres pioneiras no campo da política partidária quando participaram da elaboração da nova Constituição Federal em 1987/88, tem feito história na política local e isso tem contribuído para desmistificar a ideia de que a mulher e principalmente a do Norte do Brasil, não possui capacidade de se inserir nos espaços de poder político. Ao longo de suas jornadas como parlamentares, Beth Azize, Eunice Michiles, Conceições Sampaio e Vanessa Grazziotin, apesar dos diferentes momentos da história política em que estiveram presente na casa parlamentar foram mulheres que lutaram através de seus discursos para se firmarem como parlamentares dentro de um espaço composto pela maioria de homens.

Um estudo nessa perspectiva vem contribuir com as discussões que envolvem a condição feminina não só na sociedade em que estão inseridas, mas com a relação a sua luta pelo direito de exercer de forma igualitária, sua função como parlamentar. Deve-se reconhecer por fim, que embora no Brasil possua uma política de cota para as mulheres o parlamento continua com um déficit de mulheres o que contribui com a desigualdade de gênero na política representativa seja na Câmara Municipal de Manaus, na Assembleia Legislativa do Estado do Amazonas, quanto na Câmara Federal e Senado.

\section{REFERÊNCIAS}

ARENDT, Hannah. A condição humana. Tradução Roberto Raposo- 11.ed - Rio de Janeiro. Forense Universitária, 2010.

ARISTÓTELES. Política. Tradução de Mário da Gama Kury, Brasília, Editora Universidade de Brasília, 1985.

BRASIL. Lei no 9100 de 29 de setembro de 1995. Estabelece normas para a realização das eleições municipais de 3 de outubro de 1996, e dá outras providências. Brasília, 1996. Disponível em http://www.planalto.gov.br/ccivil_03/leis/19100.htm. Acesso em 25/04/2018.

BRASIL. Lei no 9504 de 30 de setembro de 1997. Estabelece normas para as eleições. Brasília, 1997. Disponível em http://www.planalto.gov.br/ccivil_03/leis/L9504.htm. Acesso em 09/02/2015. Acesso em 10/11/2016.

BRASIL. Lei 12034 de 29 de setembro de 2009. Altera as Leis nos 9.096, de 19 de setembro de 1995 Leis dos Partidos Políticos, 9.504, de 30 de setembro de 1997, que estabelece normas para as eleições, e 4.737, de 15 de julho de 1965 - Códigos Eleitoral. Brasília, 2009. Disponível em http://www.planalto.gov.br/ccivil_03/_ato2007-2010/2009/lei//12034.htm. Acesso em 25/04/2018.

BOBBIO, Norberto. Dicionário de política I. Norberto Bobbio, Nicola Matteucci e Gianfranco Pasquino; trad. Carmen C, Varriale; coord. trad. João Ferreira; rev. geral João Ferreira e Luis Guerreiro Pinto Cacais. - Brasília: Editora Universidade de Brasília, 1a. Ed., 1998.

CHAUI, Marilena. Filosofia: Volume único: 1.ed. - São Paulo: Ática, 2010.

COSTA, Ana Alice Alcântara. As donas no poder: Mulher e política na Bahia- Salvador: NEIM/UFBAAssembleia Legislativa da Bahia. 1998.

COSTA, Heloísa Lara Campos da. As Mulheres e o poder na Amazônia - Manaus: EDUA, 2005.

FERREIRA, Maria Mary. Nos bastidores da Tribuna: mulher política e poder no Maranhão. UFMA. São Luís, 2010.

GROSSI, Mírian Pillar; MIGUEL, Sônia Malheiros. Transformando a diferença: as Mulheres na política. Revista Estudos Feministas Vol.9, № 2, p. 167-206. Florianópolis, 2000. 
MIGUEL, Luís Felipe. BIROLLI, Flávia. Feminismo e Política: uma introdução - 1. Ed. São Paulo: Bomtempo, 2014.

MILL, John Stuart. A sujeição das mulheres. Coleção grandes obras do pensamento universal. Editora: Escala 2006.

PERROT, Michelle. Mulheres públicas. Tradução Roberto Leal Ferreira. São Paulo: Fundação Editora da UNESP, 1998.

PINHEIRO, Luana Simões. Vozes femininas na política: uma análise sobre mulheres parlamentares no Pós- Constituinte. Dissertação de Mestrado - Universidade de Brasília, 2006.

ROSSI, Amanda. MAZOTTE, Natália. Partidos recorrem a candidaturas fantasmas para preencher cota de 30\% para mulheres. Disponível em http://www.generonumero.media/partidosrecorrem-candidatas-fantasmas-para-preencher-cota-de-30-para-mulheres/>. Acesso em 29 set. 2016.

SAFFIOTI, Heleieth lara Bongiovani. Gênero, patriarcado, violência. Fundação Perseu Abramo, 2004.

SOUZA, Michelle Rabelo de. A Presença da Mulher na Política: o protagonismo de Eunice Michiles no Senado Federal. 2016. Dissertação (Mestrado em Sociedade e Cultura na Amazônia) Universidade Federal do Amazonas.

STEARNS, Peter N. História das relações de gênero / [tradução Mirna Pinsky] - 2.ed., 1a reimpressão. - São Paulo: Contexto, 2012.

TABAK, Fanny. Mulheres públicas: participação política e poder. Rio de Janeiro: Letra Capital, 2002. TORRES, Iraildes C. As novas Amazônidas. Manaus: Editora da universidade Federal do Amazonas, 2005.

Arquitetura do poder: memória de Gilberto Mestrinho - Manaus: editora da Universidade Federal do Amazonas, 2009. 